Journal of Management and Bussines (JOMB)

Volume 1, Nomor 1, Juni 2019

p-ISSN : 2656-8918

e-ISSN: $2684-8317$

DOI : https://doi.org/10.31539/jomb.v1i1.656

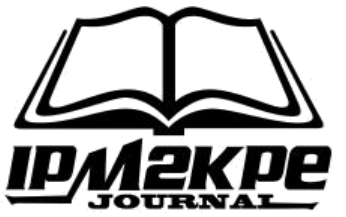

\title{
PENERAPAN PROSES SELEKSI DAN PENEMPATAN KERJA TERHADAP KINERJA KARYAWAN
}

\author{
Retla Della Rustawan ${ }^{1}$, Nor Norisanti ${ }^{2}$, Kokom Komariah ${ }^{3}$ \\ Universitas Muhammadiyah Sukabumi ${ }^{1,2,3}$ \\ Email:retla2019@gmail.com ${ }^{1}$
}

\begin{abstract}
ABSTRAK
Tujuan penelitian ini adalah untuk mengetahui pengaruh penerapan proses seleksi dan penempatan kerja terhadap kinerja karyawan. Metode yang digunakan dalam penelitian ini menggunakan metode deskriptif dan metode asosiatif. Teknik pengumpulan data yang dilakukan peneliti dalam penelitian yaitu melalui observasi, wawancara angket, dokumentasl dan studi kepustakaan. Teknik analisa data dimulai dari penyusunan data, tabulasi data hingga tahap pengujian. Hasil penelitian, berdasarkanperhitungan pengkategorian data yang didapatkan bahwa nilai proses seleksi sebesar 571 berada diantara kriteria sedang dan tinggi. Hal ini menunjukan bahwa proses seleksi yang terjadi pada PT. Bank Pembangunan Jawa Barat dan Banten Tbk. Cabang Sukabumi sudah tergolong tinggi. Hal ini diartikan bahwa proses seleksi berpengaruh untuk perusahaan. Berdasarkan perhitungan pengkategorian data yang didapatkan bahwa nilai penempatan kerja sebesar 359 berada diantara kriteria rendah dan sedang. Hal ini menunjukan bahwa penempatan kerja yang terjadi pada PT. Bank Pembangunan Jawa Barat dan Banten Tbk. Cabang Sukabumi tergolong sedang. Simpulan, seleksi dan penempatan kerja terhadap kinerja karyawan memiliki pengaruh yang positif dan signifikan
\end{abstract}

Kata Kunci: Penerapan Proses Seleksi, Penempatan Kerja dan Kinerja Karyawan.

\begin{abstract}
The purpose of this study was to determine the effect of the application of work selection and placement processes on employee performance. The method used in this study uses descriptive methods and associative methods. Data collection techniques conducted by researchers in the study are through observation, questionnaire interviews, documentation and literature study. The data analysis technique starts from compiling data, tabulating data until the testing phase. The results of the study, based on the calculation of the categorization of data found that the value of the selection process is 571 between the criteria of medium and high. This shows that the selection process that occurred at PT. West Java and Banten Tbk Development Bank. Sukabumi Branch is already high. This means that the selection process has an effect on the company. Based on the calculation of categorization of data obtained that the value of work placements of 359 is between the criteria of low and medium. This shows that work placements that occur at PT. West Java and Banten Tbk Development Bank. Sukabumi Branch is classified as medium. Conclusions, selection and job placement on employee performance have a positive and significant effect
\end{abstract}

Keywords: Application of Selection Process, Job Placement and Employee Performance 


\section{PENDAHULUAN}

PT. Bank Pembangunan Daerah Jawa Barat dan Banten Tbk. dengan Akta No. 4 Tahun 1999 yang dibuat dihadapan Ny. Popy Kuntari Sutresna SH. Notaris di Bandung tanggal 8 April 1999 berikut Akta Perbaikan Nomor 18 Tanggal 31 Maret 2015 dibuat oleh Notaris R.Tendy Suwarman S.H Notaris di Bandung, sebagaimana terdapat dari sejarah umum PT. Bank Pembangunan Jawa Barat dan Banten Tbk.

Berdasarkan tabel rata-rata penilaian kinerja seluruh karyawan diatas menunjukkan bahwa kinerja karyawan pada PT. Bank Pembangunan Jawa Barat dan Banten Tbk. Cabang Sukabumi terlihat baik, namun dilihat dari tiga bulan terakhir terjadi penurunan pada kinerja karyawan dari bulan Juli sebesar 85\%, Agustus $83 \%$ dan September $82,5 \%$. Permasalahan tersebut diduga disebabkan oleh proses seleksi yang dilakukan perusahaan belum terealisasikan dengan baik maka dirasa tidak sesuai karena adanya calon karyawan yang melamar belum memiliki pengalaman kerja sebelumnya sehingga membutuhkan proses adaptasi yang cukup lama walaupun perusahaan sudah memberikan pelatihan sebelum memasuki pekerjaan di lapangan. Adapun penyebab lainnya yaitu diduga oleh penempatan kerja, perusahaan tidak menempatkan karyawan sesuai dengan kemampuan yang dimiliki. Masing-masing karyawan memiliki kepintaran dan pengetahuan yang berbeda-beda, oleh karena itu perusahaan baiknya dapat melihat karyawan dari sisi pengetahuan dan wawasan yang dimiliki, agar dapat ditempatka di posisi yang sesuai sehinga karyawan dapat memberikan kinerja yang optimal.

Penelitian ini bertujuan untuk mengetahui bagaimana penerapan peroses seleksi dan penempatan kerja terhadap kinerja karyawan pada PT. Bank Pembangunan Jawa Barat dan Banten Tbk. Cabang Sukabumi. Serta untuk mengetahui besarnya pengaruh penerapan proses seleksi dan penempatan kerja dan kinerja karyawan pada PT. Bank Pembangunan Jawa Barat dan Banten Tbk. Cabang Sukabumi. Penelitian dilaksanakan di PT. Bank Pembangunan Jawa Barat dan Banten Tbk. Cabang Sukabumi yang beralamat di Jl. Jend. A. Yani No.35 A-37 Sukabumi selama kurang lebih 9 bulan, terhitung dari bulan Oktober 2018 sampai dengan bulan Juli 2019. 


\section{KAJIAN TEORI}

Seperti yang dikemukakan oleh Rivai (2008) seleksi adalah kegiatan dalam manajemen SDM yang dilakukan setelah proses rekrutmen dilaksanakan. Hal ini berarti telah terkumpul sejumlah pelamar yang memenuhi syarat untuk kemudian dipilih mana yang dapat ditetapkan sebagai karyawan dalam suatu perusahaan. Proses pemilihan ini yang dinamakan seleksi. Adapun untuk melihat dan mengukur penerapan proses seleksi, dimensi Menurut Simamora (2004) Proses seleksi pada dasarnya memiliki empat sasaran, yaitu: 1) pendidikan,; 2) pengalaman kerja; 3) kondisi fisik; 4) kepribadian

Sejalan dengan pendapat Menurut Rivai (2009) bahwa penempatan karyawan berarti mengalokasikan para karyawan pada posisi kerja tertentu, hal ini khusus terjadi pada karyawan baru. Kepada karyawan lama yang telah menduduki jabatan atau pekerjaan termasuk sasaran fungsi penempatan karyawan dalam arti mempertahankan pada posisinya atau memindahkan pada posisi yang lain. Menurut Handoko (2008) dimensi penampatan kerja terdiri dari :

1. Kemampuan. Kemamuan terbentuk dari sejumlah kompetensi yang dimiliki seorang karyawan. Pengetahuan dan keterampilan termasuk faktor pembentukan kemampuan.seorang karyawan dalam mempunyai pengetahuan dan keterampilan yang tinggi.

2. Kecakapan. Kecakapan merupakan kemampuan dan penguasaan teknis operasional mengenai bidang tertentu yang bersifat kekaryaan. Kecakapan diperoleh melalui proses belajar dan berlatih. Kecakapan berkaitan dengan kemampuan seseorng untuk melakukan atau menyelesaikan pekerjaan-pekerjaan yang bersifat teknis.

3. Keahlian. Keahlian merupakan suatu ilmu atau pekerjaan. Keahlian terbentuk dari kepandaian, kepakaran, spesialisasi dan kepintaran. Pegawai yang mempunyai keahlian berarti pegawai tersebut ahli dan unggul dalam suatu bidang ilmu atau pekerjaan.

Pendapat Mangkunegara (2012) kinerja adalah prestasi kerja atau hasil kerja (output) baik kualitas maupun kuantitas yang dicapai SDM dalm melaksanakan tugas kerjanya sesuai dengan tanggungjawab yang diberikan kepadanya.Untuk mengukur kinerja karyawan, ada empat aspek tersebut menurut Ivancevich (2007) adalah:

1. Quanity of work (Kuantitas Kerja). Kuantitas kerja berkaitan dengan hasil jumlah yang volume kerja yang dapat diselesaikan karyawan dalam kondisi normal. 
2. Quality of work (Kualitas Kerja). Meliputi ketelitian, kerapihan, dan ketetapan dalam mengerjakan pekerjaan atau standard mutu yang ditetapkan oleh perusahaan.

3. Comperation (Kerjasama). Kemampuan kerja sama sesama rekan kerja, atasan dan bawahan untuk sama-sama mencapai tujuan perusahaan.

4. Knowledge of job (Pengetahuan Tentang Pekerjaan). Rangkaian kegiatan yang digunakan perusahaan untuk diketahui dan dipelajari oleh karyawan untuk pencapain suatu hasil tertentu.

Hubungan antara seleksi dengan kinerja karyawan didukung oleh teori yang dikemukakan oleh Martoyo (2007) menyatakan bahwa kriteria seleksi dapat dirangkum menjadi beberapa kategori yaitu, pendidikan, pengalaman kerja, kondisi fisik, dan kepribadian. Untuk mendapatkan karyawan yang memiliki kinerja yang baik, maka perusahaan harus memulainya dari seleksi karyawan, karena karyawan dapat dilihat memiliki kinerja yang baik atau tidak dari tahapan seleksi berdasarkan hasil tes.

\section{METODE PENELITIAN}

Variabel dalam penelitian terdiri dari variabel independen yaitu penerapan poses seleksi (X1) dan penempatan kerja (X2) serta variabel dependen yaitu kinerja karyawan (Y). Metode penelitian yang dipakai ialah deskriptif dan asosiatif. Paradigma penelitian menggunakan paradigma ganda dengan dua variabel independen.

Teknik pengumpulan data menggunakan observasi, wawancara, angket, dokumentasi dan studi kepustakaan. Teknik analisa data menggunakan koefisien korelasi ganda untuk mengukur hubungan antar variabel, koefisien determinasi untuk mengukur besarnya pengaruh varuabel penerapan proses seleksi dan variable penempatan kerja terhadap kinerja karyawan, analisis regresi berganda untuk mengukur konsistensi nilai variabel terikat dan uji $\mathrm{F}$ untuk menguji hipotesis.

Adapun populasi dalam penelitian ini adalah Karyawan PT. Bank Pembangunan Jawa Barat dan Banten Tbk. Cabang Sukabumi. Teknik pengambilan sampel yang digunakan oleh peneliti adalah teknik sampling jenuh semua anggota populasi dugunakan sebagai sampel. Penelitian ini menggunakan uji validitas dengan rumus product moment dan uji reliabilitas dengan rumus cronbach's alpha. Angket yang disebar menggunakan skala Likert dengan pernyataan positif. 


\section{HASIL PENELITIAN}

\section{Uji Validitas}

Uji Validitas adalah suatu taraf dimana alat pengukur dapat mengukur apa yang seharusnya diukur sehingga suatu penelitian yang menggunakan kuisioner sebagian besar pengukurannya perlu diuji validitasnya. Biasanya syarat minimum untuk dianggap memenuhi syarat adalah kalau $r=0,3$. Jadi jika korelasi antara butir dengan intrumen dinyatakan tidak valid. Berdasarkan pengujian validitas menggunakan bantuan software SPSS 24 diperoleh hasil sebagai berikut:

Tabel 1

Hasil uji validitas Seleksi

\begin{tabular}{cccc}
\hline Item & r hitung & r kritis & Keterangan \\
\hline 1. & 0,604 & 0,3 & Valid \\
\hline 2. & 0,717 & 0,3 & Valid \\
\hline 3. & 0,730 & 0,3 & Valid \\
\hline 4. & 0,581 & 0,3 & Valid \\
\hline
\end{tabular}

Sumber: hasil penelitian, diolah, 2019

Tabel 2

Hasil Uji Validitas Penempatan Kerja

\begin{tabular}{cccc}
\hline Item & r hitung & r kritis & Keterangan \\
\hline 1. & 0,747 & 0,3 & Valid \\
\hline 2. & 0,653 & 0,3 & Valid \\
\hline 3. & 0,595 & 0,3 & Valid \\
\hline
\end{tabular}

Sumber: hasil penelitian diolah, 2019

Tabel 3

Hasil Uji Validitas Kinerja Karyawan

\begin{tabular}{cccc}
\hline Item & r hitung & r kritis & Keterangan \\
\hline 1. & 0,653 & 0,3 & Valid \\
\hline 2. & 0,641 & 0,3 & Valid \\
\hline 3. & 0,607 & 0,3 & Valid \\
\hline 4. & 0,406 & 0,3 & Valid
\end{tabular}

Sumber: hasil penelitian diolah, 2019

Berdasarkan data table diatas, dapat diketahui bahwa nilai korelasi antara skor item variabel Seleksi $\left(\mathrm{X}_{1}\right)$, Penempatan Kerja $\left(\mathrm{X}_{2}\right)$ dan Kinerja Karyawan $(\mathrm{Y})$ seluruh item pada hasil pengujian tersebut memiliki skor diatas 0,3 sehingga seluruh butir instrumen Seleksi $\left(\mathrm{X}_{1}\right)$, Penempatan Kerja $\left(\mathrm{X}_{2}\right)$ dan Kinerja Karyawan $(\mathrm{Y})$ dinyatakan valid. 


\section{Uji Reliabilitas}

Hasil uji realibitas menggunakan rumus Cronbach's Alpha serta dengan bantuan software SPSS 24 diperoleh hasil perhitungan yang disajikan pada tabel berikut ini.

Tabel 4

Hasil Uji Reliabilitas Seleksi

Reliability Statistics

\begin{tabular}{rr}
\hline Cronbach's Alpha & N of Items \\
\hline, 556 & 4
\end{tabular}

Sumber: Hasil Pengolahan Data, 2019

Tabel 5

Hasil Uji Reliabilitas Penempatan Kerja

\begin{tabular}{rr}
\hline \multicolumn{2}{c}{ Reliability Statistics } \\
\hline Cronbach's Alpha & N of Items \\
\hline, 362 & 3 \\
\hline
\end{tabular}

Sumber: Hasil Pengolahan Data, 2019

Tabel 6

Hasil Uji Realibitas Kinerja Karyawan

\begin{tabular}{|c|c|}
\hline \multicolumn{2}{|c|}{ Reliability Statistics } \\
\hline Cronbach's & \\
\hline Alpha & $\mathrm{N}$ of Items \\
\hline ,331 & 4 \\
\hline
\end{tabular}

Dari tabel pengujian data di atas, di peroleh hasil yang menunjukan $\alpha$ hitung > $\alpha$ standar $(0,3)$ sehingga dapat disimpulkan bahwa variabel-variabel yang dipakai dalam penelitian ini adalah reliabel. Dengan demikian maka jelaslah bahwa variabel-variabel tersebut dapat digunakan untuk penelitian selanjutnya karena dapat diandalkan.

\section{Hasil Analisis Regresi Linear Berganda}

Regresi linear berganda digunakan untuk mengetahui seberapa besar pengaruh faktor yang digunakan dalam model penelitian budaya kizen dan reward terhadapkinerja karyawan. Hasil regresi linear berganda dapat dilihat pada tabel 7 sebagai berikut: 
Tabel 7

Analisis Regresi Linear Berganda

\begin{tabular}{|c|c|c|c|c|c|c|}
\hline \multicolumn{7}{|c|}{ Coefficients $^{\mathrm{a}}$} \\
\hline \multirow{2}{*}{\multicolumn{2}{|c|}{ Model }} & Unstandardize & Coefficients & $\begin{array}{l}\text { Standardized } \\
\text { Coefficients }\end{array}$ & & \\
\hline & & $\mathrm{B}$ & Std. Error & Beta & $\mathrm{t}$ & Sig. \\
\hline \multirow[t]{3}{*}{1} & (Constant) & ,695 & 1,030 & & ,675 &, 504 \\
\hline & $\mathrm{x} 1$ &, 474 & ,061 & ,608 & 7,829 &, 000 \\
\hline & $\mathrm{x} 2$ & ,611 &, 095 & ,498 & 6,416 &, 000 \\
\hline
\end{tabular}

a. Dependent Variable: y

Sumber: hasil penelitian, diolah, 2019

Berdasarkan tabel tersebut diatas, maka dapat diketahui nilai dari persamaan regresi linier ganda tersebut, adalah sebagai berikut: $a=0,695, b_{1}=0,474, b_{2}=0,611$. Selanjutnya, didapat persamaan regresi linier berganda untuk dua predikator (seleksi dan penempatan kerja) adalah:

$\mathrm{Y}^{*}=0,695+0,474 \mathrm{X}_{1}+0,611 \mathrm{X}_{2}$

Berdasarkan dari persamaan diatas, diketahui terdapat pegaruh positif antara seleksi (Variabel $\mathrm{X}_{1}$ ) dan penempatan kerja $\left(\right.$ Variabel $\mathrm{X}_{2}$ ) terhadap Kinerja Karyawan (Variabel Y). Ini dapat diartikan bahwa hasil penelitian ini menunjukkan bahwa Seleksi dan Penempatan Kerja memiliki pengaruh positif terhadap Kinerja Karyawan. Adapun koefisien regresi untuk Seleksi sebesar 0,474 lebih kecil dari pada koefisien regresi untuk Penempatan Kerja sebesar 0,611.

\section{Hasil koefisien determinasi}

Tabel 8

Hasil Koefisien Determinasi

\begin{tabular}{|c|c|c|c|c|}
\hline \multicolumn{5}{|c|}{ Model Summary } \\
\hline Model & $\mathrm{R}$ & R Square & $\begin{array}{c}\text { Adjusted R } \\
\text { Square }\end{array}$ & $\begin{array}{l}\text { Std. Error of the } \\
\text { Estimate }\end{array}$ \\
\hline 1 & $.570^{\mathrm{a}}$ & .325 & .295 & 1.806 \\
\hline
\end{tabular}

a. Predictors: (Constant), reward, budaya kaizen

Sumber: data primer (kuisioner) 2019

Hasil tabel 8 diatas model summary besarnya adjusted $\mathrm{R}^{2}$ yaitu 0,295 ; hal ini berarti 29,5\% variasi kinerja karyawan dapat dijelaskan oleh variasi dari dua variabel independen Budaya kaizen dan Reward sedangkan sisanya 70.5\% (100\%$29,5 \%=70,5 \%$ ) dari faktor yang tidak diteliti. 


\section{Hasil Koefisien Korelasi Ganda}

Berdasarkan perhitungan koefisien determinasi yang telah peneliti lakukan, diketahui bahwa nilai $\mathrm{Kd}=79,6 \%$. Maka dapat disimpulkan bahwa pengaruh dan penempatan kerja terhadap kinerja karyawan yaitu kuat. Korelasi antara seleksi dan penempatan kerja sebesar 0,892, pengaruh seleksi terhadap kinerja karyawan sebesar 0,755, pengaruh penempatan kerja terhadap kinerja karyawan sebesar 0,678 dan besarnya pengaruh seleksi dan penempatan kerja terhadap kinerja karyawan sebesar $79,6 \%$, sedangkan sisanya sebesar $20,5 \%$ dipengaruhi oleh faktor lain yang tidak termasuk dalam penelitian ini.

\section{Hasil Uji Hipotesis}

Tabel 9

Uji Hipotesis

\begin{tabular}{|c|c|c|c|c|c|c|}
\hline \multicolumn{7}{|c|}{ 1. ANOVA $^{\mathbf{a}}$} \\
\hline Model & & Sum of Squares & Df & Mean Square & $\mathrm{F}$ & Sig. \\
\hline \multirow[t]{3}{*}{1} & Regression & 106,633 & 2 & 53,317 & 72,349 &, $000^{\mathrm{b}}$ \\
\hline & Residual & 27,267 & 37 &, 737 & & \\
\hline & Total & 133,900 & 39 & & & \\
\hline
\end{tabular}

a. Dependent Variable: y

b. Predictors: (Constant), $\mathrm{x} 2, \mathrm{x} 1$

Sumber: hasil penelitian, diolah, 2019

Berdasarkan perhitungan di atas, didapatkan hasil $\mathrm{F}$ hitung variabel $\mathrm{X}_{1}$ (seleksi), $\mathrm{X}_{2}$ (penempatan kerja) dan $\mathrm{Y}$ (kinerja karyawan) adalah sebesar 72,349 Selanjutnya nilai $\mathrm{F}$ hitung tersebut dibandingkan dengan nilai $\mathrm{F}$ tabel. $\mathrm{F}$ tabel dicari pada tabel yang tertera pada lampiran dengan didasarkan pada $\mathrm{dk}$ pembilang $=\mathrm{k}$ dan $\mathrm{dk}$ penyebut $=(n-k-1)$ dan taraf kesalahan yang ditetapkan. Adapun taraf kesalahan yang ditetapkan adalah sebesar $5 \%$, jadi $\mathrm{dk}$ pembilang $=2$, dan $\mathrm{dk}$ penyebut $=37$, sehingga diperoleh nilai $\mathrm{F}$ tabel $=3,25$.

\section{PEMBAHASAN}

PT. Bank Pembangunan Daerah Jawa Barat dan Banten Tbk. dengan Akta No. 4 Tahun 1999 yang dibuat dihadapan Ny. Popy Kuntari Sutresna SH. Notaris di Bandung tanggal 8 April 1999 berikut Akta Perbaikan Nomor 18 Tanggal 31 Maret 2015 dibuat oleh Notaris R.Tendy Suwarman S.H Notaris di Bandung, sebagaimana terdapat dari sejarah umum PT. Bank Pembangunan Jawa Barat dan Banten Tbk. 
Pendirian Bank Pembangunan Daerah Jawa Barat dilatar belakangi oleh Peraturan Pemerintah Republik Indonesia nomor 33 tahun 1960 tentang penentuan perusahaan di Indonesia milik Belanda yang dinasionalisasi. Salah satu perusahaan milik Belanda yang berkedudukan di Bandung yang dinasionalisasi yaitu NV Denis (De Erste Nederlansche Indische Shareholding) yang sebelumnya perusahaan tersebut bergerak dibidang bank hipotek. Sebagai tindak lanjut dari Peraturan Pemerintah nomor 33 tahun 1961 Pemerintah Provinsi Jawa Barat dengan Akta Notaris Noezar nomor 152 tanggal 21 Maret 1961 dan nomor 184 tanggal 13 Mei 1961 dan dikukuhkan dengan Surat Keputusan Gubernur Provinsi Jawa Barat nomor 7/GKDH/BPD/61 tanggal 20 Mei 1961, mendirikan PD Bank Karya Pembangunan dengan modal dasar pertama kali berasal dari Kas Daerah sebesar Rp. 2.500.0000.000,-.

Berdasarkanperhitungan pengkategorian data yang didapatkan bahwa nilai proses seleksi sebesar 571 berada diantara kriteria sedang dan tinggi. Hal ini menunjukan bahwa proses seleksi yang terjadi pada PT. Bank Pembangunan Jawa Barat dan Banten Tbk. Cabang Sukabumi sudah tergolong tinggi. Hal ini diartikan bahwa proses seleksi berpengaruh untuk perusahaan.

Berdasarkan perhitungan pengkategorian data yang didapatkan bahwa nilai penempatan kerja sebesar 359 berada diantara kriteria rendah dan sedang. Hal ini menunjukan bahwa penempatan kerja yang terjadi pada PT. Bank Pembangunan Jawa Barat dan Banten Tbk. Cabang Sukabumi tergolong sedang. Hal ini diartikan bahwa penempatan kerja yang diakukan perusahaan tidak terlalu berpengaruh.

\section{SIMPULAN}

Berdasarkan hasil penelitian, pembahasan dan teknik analisis data yang peneliti lakukan mengenai Seleksi dan Penempatan Kerja terhadap Kinerja Karyawan pada PT. Bank Pembangunan Jawa Barat dan Banten Tbk. Cabang Sukabumi, maka peneliti dapat mengambil simpulan sebagai berikut:

1. Seleksi yang dilakukan oleh PT. Bank Pembangunan Jawa Barat dan Banten Tbk. Cabang Sukabumi kepada calon karyawannya berada pada kategori tinggi. Hal ini menunjukan bahwa seleksi yang dilaksanakn PT. Bank Pembangunan Jawa Barat dan Banten Tbk. Cabang Sukabumi mampu membuat calon karyawan melalui tahapan proses seleksi yang sudah ditetapkan oleh perusahaan. PT. Bank 
Pembangunan Jawa Barat dan Banten Tbk. Cabang Sukabumi memiliki kriteria dan standard bagi para calon karyawannya sebelum mereka menindaklanjuti untuk tahap-tahap berikutnya. Karyawan yang lolos seleksi sesuai dengan standard yang ditetapkan, yang akan melanjutkan ke tahap-tahap selanjutnya. Perlunya seleksi dilakukan agar perusahaan dapat memiliki SDM yang baik dan berkualitas yang dapat berkontribusi pada pencapaian tujuan perusahaan.

2. Penempatan kerja yang diberikan kepada kayawan pada PT. Bank Pembangunan Jawa Barat dan Banten Tbk. Cabang Sukabumi berada pada kategori sedang. Hal ini dapat disimpulkan bahwa PT. Bank Pembangunan Jawa Barat dan Banten Tbk. Cabang Sukabumi sudah memberikan penempatan kerja kepada karyawannya dengan baik dan dengan tujuan untuk membuat karyawannya semakin giat dan sesuai dengan keinginan perusahaan dalam menjalankan tugas yang diberikan perusahaan. Hal ini haruslah dipertahankan dan ditingkatkan lagi karena penempatan kerja bagi karyawan berperan untuk kemajuan perusahaan.

3. Kinerja Karyawan yang dihasilkan berada pada kategori tinggi. Hal ini dapat disimpulkan bahwa karyawan sudah memiliki kinerja yang baik. Semakin banyak karyawan yang memberikan kinerja baik akan semakin banyak pula SDM yang berkualitas yang dimiliki oleh perusahaan tersebut. Kinerja Karyawan PT. Bank Pembangunan Jawa Barat dan Banten Tbk. Cabang Sukabumi sudah tergolong tinggi maka dapat dikatakan kinerja karyawannya sudah baik.

4. Seleksi dan Penempatan Kerja terhadap Kinerja Karyawan pada PT. Bank Pembangunan Jawa Barat dan Banten Tbk. Cabang memiliki pengaruh yang positif dan signifikan, hal tersebut dapat disimpulkan setelah pengujian hipotesis, dan halhal lain yang mempengaruhi Kinerja Karyawan pada PT. Bank Pembangunan Jawa Barat dan Banten Tbk. Cabang Sukabumi yang dipengaruhi oleh faktor lain yang tidak diteliti dalam penelitian ini. Maka dari itu, apabila proses seleksi dilakukan dengan baik dan penempatan kerja yang sesuai maka dapat meningkatkan kinerja karyawan PT. Bank Pembangunan Jawa Barat dan Banten Tbk. Cabang Sukabumi. 


\section{DAFTAR PUSTAKA}

Handoko. (2008). Manajemen Personalia Sumber Daya Manusia. Edisi Kedua,Yogyakarta, Penerbit : BPFE

Ivancevich, J. M. et all. (2007). Perilaku \& Manajemen Organisasi. Erlangga :Jakarta. Mangkunegara, Anwar. (2012). Manajemen Sumber Daya Manusia. Bandung : PT. Remaja Rosdakarya.

Rivai, Veithzal. (2008). Manajemen Sumber Daya Manusia untuk perusahaan. PT.Raja Grafindo Perkasa.

Simamora, Henry. (2004). Manajemen Sumber Daya Manusia. Edisi Ketiga, Yogyakarta, STIE YPN

Susilo, Martoyo. (2007). Manajemen Sumber Daya Manusia, Edisi 5, Cetakan Pertama. BPFE. 